\title{
STRATEGI KOPING PADA PELANGGAR QANUN JINAYAH DITINJAU DARI JENIS KELAMIN
}

\author{
Affan Maulana Ghiffari* \\ *Universitas Syiah Kuala \\ **Universitas Syiah Kuala
}

Haiyun Nisa**

DOI: https://doi.org/10.21009/JPPP.081.06

\author{
Alamat Korespondensi: \\ haiyunnisa@unsyiah.ac.id
}

\begin{abstract}
Qanun Jinayah violators who are serve a period of detention experience various psychological problems such as depression, anxiety, phobias, and anti-social personality. To be able deal with these various problems, Qanun Jinayat violators need a coping strategy. The purpose of this study was to determine the differences of coping strategies in Qanun Jinayat violators in terms of gender. The sample in this study consisted of 13 male and 13 female who violated Qanun Jinayat in several prison in Aceh province. To identify coping strategies used by Jinayat lawbreakers, researcher used the WCCL-ASIAN scale with results of data analysis showed $p=$ 0,588 for problem focused coping strategies, the results of data analysis showed $p=0,551$ for seek social support coping strategies, the results of data analysis showed $p=0,231$ for blame self coping strategies, the results of data analysis showed $p=0,300$ for wishful thinking coping strategies, and results data analysis shows $p=0,036$ for avoidance coping strategies. The results showed that there were no differences in problem focused, seek social support, blame self, and wishful thinking coping strategies, but there are difference in avoidance coping strategies for Qanun Jinayah violators, both male and female.
\end{abstract}

Keywords: coping strategies, qanun jinayah, prisoners

\section{Pendahuluan}

Provinsi Aceh memiliki mayoritas penduduk yang beragama Islam. Tidak heran jika kehidupan masyarakat serta budaya di Aceh sangat dipengaruhi oleh agama Islam (Hamdani, 2013). Provinsi Aceh diberikan keistimewaan dan otonomi khusus, salah satunya kewenangan untuk menegakkan Syariat Islam. Syariat Islam ditegakkan melalui hukum khusus yang disebut dengan Qanun. UU nomor 11 Tahun 2006 tentang Pemerintahan Aceh mendefinisikan Qanun sebagai peraturan daerah yang mengatur penyelenggaraan pemerintahan dan kehidupan masyarakat di Provinsi Aceh (Dinas Syariat Islam Aceh, 2015).
Qanun Aceh nomor 6 tahun 2014 menyebutkan bahwa Qanun mengandung hukum yang mengatur tentang syariat Islam. Hukum ini disebut dengan Jinayah (hukum pidana). Qanun Jinayah mengatur tentang jarimah dan 'uqubat. Qanun Aceh nomor 6 tahun 2014 mendefinisikan jarimah sebagai perbuatan yang dilarang oleh Syariat Islam, sedangkan 'Uqubat merupakan hukuman yang diberikan kepada pelaku jarimah (Dinas Syariat Islam Aceh, 2015).

Dinas Syariat Islam Aceh (2015) menjelaskan bahwa jenis pelanggaran yang termasuk kedalam jarimah diantaranya adalah mengkonsumsi khamar (minuman memabukkan), maisir (perbuatan yang mengandung unsur taruhan), zina (persetubuhan antara laki-laki dan perempuan 
tanpa ikatan perkawinan secara sukarela), khalwat (berada pada tempat tertutup atau tersembunyi antara laki-laki dan perempuan yang halal untuk dinikahi tanpa ikatan pernikahan), liwath (persetubuhan antara sesama laki-laki dengan kerelaan kedua belah pihak), musahaqah (persetubuhan antara sesama perempuan dengan kerelaan kedua belah pihak), ikhtilat (kegiatan bermesra-mesraan antara laki-laki dan perempuan yang bukan suami istri), pelecehan seksual (perbuatan asusila yang sengaja dilakukan terhadap orang lain secara paksa), dan pemerkosaan (hubungan seksual dengan kekerasan atau paksaan maupun ancaman).

Salah satu contoh kasus pelanggaran Qanun Jinayah terdapat di kota Jantho, Aceh Besar. Tersangka kasus pelecehan seksual berinisial D terbukti melakukan pelecehan seksual terhadap 3 orang anak dibawah umur. D melakukan pelanggaran terhadap pasal 47 Qanun nomor 6 Tahun 2014 tentang hukum Jinayah dan menerima hukuman penjara sekitar delapan bulan dan 120 kali cambukan (Kusmawan, 2017).

Contoh kasus lainnya adalah dua laki-laki yang tertangkap basah melakukan hubungan sesama jenis dalam sebuah rumah kost. Kedua laki-laki tersebut dinyatakan bersalah dan dijerat dengan Pasal 63 ayat 1 Qanun nomor 7 Tahun 2014 tentang hukum Jinayah dan menerima hukuman 83 kali cambukan setelah dikurangi 2 cambukan. Dua cambukan yang dikurangi diganti dengan 2 bulan tahanan (Warsidi, 2017).

Berdasarkan keterangan dari keluarga, kondisi mental kedua laki-laki tersebut tidak stabil setelah menjalani hukuman. Salah satu anggota keluarga tersangka pelanggar Qanun Jinayah tersebut menyatakan bahwa meskipun kondisi fisik tersangka tidak bermasalah, tersangka mengalami permasalahan psikologis dan merasa tidak memiliki harapan dalam hidup. Tersangka ingin lebih mendekatkan diri kepada Tuhan, dan menempuh pendidikan di pesantren (Meilana, Kamilah, \& Hari, 2017).

Dari hasil kedua contoh kasus tersebut dapat disimpulkan bahwa pelanggar Qanun Jinayah mengalami masalah psikologis, bahkan ada yang merasa bahwa hidupnya sudah tidak memiliki harapan lagi. Selain permasalahan psikologis, pelanggar Qanun Jinayah yang mendapatkan hukuman cambuk di hadapan masyarakat umum juga merasakan malu yang sangat besar dan rasa penyesalan. Hal ini sejalan dengan penelitian yang dilakukan sebelumnya bahwa bagi individu yang mendapatkan hukuman penjara akan mengalami permasalahan psikologis seperti depresi, kecemasan, fobia dan anti-social personality (Ardilla \& Herdiana, 2013). Keterbatasan dalam berbagai hal seperti ruang dan gerak, serta aktivitas selama berada di penjara memungkinkan pelanggar hukum untuk mengalami gangguan psikologis, mulai dari stres ringan sampai bunuh diri (Ula, 2014).

Masalah-masalah yang dijelaskan di atas dapat berbeda antara laki-laki dan perempuan. Penelitian yang dilakukan oleh Weissman, DeLamater, dan Lovejoy menunjukkan bahwa pelanggar hukum perempuan memiliki gangguan mental dan depresi yang lebih tinggi dibandingkan dengan laki-laki (dalam Aborisade \& Fayemi, 2016). Lebih lanjut dijelaskan bahwa pelanggar perempuan sering mengalami depresi, stres, gangguan mental, gangguan tidur, dan kecemasan (Boxer, Middlemass, \& Delorenzo, dalam Aborisade \& Fayemi, 2016). Butterfield (dalam Gussak, 2009) juga menemukan bahwa perempuan lebih rentan mengalami depresi dibandingkan laki-laki. Hal ini dapat disebabkan oleh masalah atau penyebab timbulnya depresi yang tidak diketahui atau tidak ditangani (Blitz, Wolff, Pan, \& Pogorzelski, dalam Gussak, 2009).

Berbagai masalah yang muncul pada pelanggar Qanun Jinayah yang menerima hukuman, menuntut individu pelanggar tersebut untuk dapat menggunakan strategi koping yang sesuai agar dapat menghadapi permasalahanpermasalahan tersebut. Hal ini diperlukan agar individu tersebut dapat meminimalkan atau bahkan menghilangkan masalah psikologis yang ditimbulkan dari masalah-masalah yang dihadapi selama atau sesudah menerima hukuman.

Konteks atau tempat situasi stres yang dialami oleh individu akan menentukan strategi koping yang akan digunakan oleh individu tersebut (Reed, Alenanzi, \& Potterton, 2009). Lebih lanjut 
Reed, dkk (2009) menjelaskan bahwa terdapat dua strategi koping utama yang digunakan oleh individu, yaitu: bertindak langsung pada situasi yang menimbulkan masalah, biasa disebut sebagai problem-focused koping (koping yang berfokus pada masalah), dan mengontrol emosi yang disebabkan oleh situasi, biasa disebut emotionfocused koping (sebagai koping yang berfokus pada emosi).

Buyuksahin (2009) dalam penelitiannya menjelaskan bahwa laki-laki cenderung lebih banyak mengonsumsi alkohol dan narkoba dibandingkan dengan perempuan sebagai salah satu bentuk strategi koping yang digunakan. Berbeda dengan pelanggar hukum perempuan, pelanggar hukum laki-laki muda lebih sering menggunakan strategi yang berfokus pada masalah dibandingkan dengan strategi yang berfokus pada emosi (Mohino, Kirchner, \& Forns, 2004). Melendez, Mayordomo, Sancho, dan Thomas (2012) juga mendukung penjelasan Mohino, dkk (2014) dengan menjelaskan bahwa perempuan lebih cenderung menggunakan strategi koping yang berfokus pada emosi dan mencari bantuan dibanding kan dengan laki-laki. Gentry, Chung, Aung, Keller, Heinrich, dan Maddock (2007) menjelaskan lebih lanjut bahwa perempuan cenderung menggunakan strategi koping yang adaptif, sedangkan laki-laki cenderung menggunakan strategi maladaptif dan menghindar.Berbeda dengan penelitian sebelumnya, penelitian yang dilakukan oleh Santacana, Kirchner, Abad, dan Amador (2012) menemukan bahwa tidak terdapat perbedaan jenis koping yang digunakan laki-laki dan perempuan. Penelitian oleh Hampel dan Petermann (2005) juga menyebutkan bahwa baik remaja laki-laki dan perempuan, serta anak perempuan dari semua rentang usia memiliki nilai yang lebih rendah pada strategi koping adaptif dan lebih tinggi pada strategi koping yang tidak sesuai atau maladaptif. Contoh strategi koping yang adaptif adalah ketika individu menggunakan strategi koping yang berfokus pada masalah ketika salah satu anggota keluarganya meninggal, sedangkan contoh koping yang maladaptif adalah mengkonsumsi alkohol atau narkoba untuk menenangkan diri ketika menghadapi masalah.

Mengingat pentingnya strategi koping dalam mengatasi dampak negatif pada kondisi psikologis pelanggar Qanun Jinayah yang menerima hukuman, menjadi penting pula untuk dapat mengidentifikasi strategi koping yang digunakan oleh pelanggar laki-laki maupun perempuan. Hal ini menjadi penting agar strategi koping tersebut dapat diberikan bantuan atau difasilitasi oleh pihak-pihak terkait. Bantuan tersebut diharapkan dapat membantu pelanggar Qanun Jinayah untuk menjalankan kehidupannya dengan lebih baik dan tanpa ada hambatan. Hal inilah yang mendasari peneliti untuk mengetahui bagaimana strategi koping yang digunakan oleh pelanggar qanun jinayah ditinjau dari jenis kelamin.

\section{Metode Penelitian}

Penelitian ini menggunakan pendekatan kuantitatif dengan jenis penelitian komparasi. Populasi dalam penelitian ini adalah seluruh pelanggar Qanun Jinayah. Teknik pengambilan sampel yang digunakan dalam penelitian ini menggunakan teknik purposive sampling.

Dalam penelitian ini peneliti menggunakan instrumen yang sudah terstandar, yaitu The Way of Coping Checklist Revision-Asian Version (WCCL-ASIAN) yang di kembangkan oleh Sawang, dkk (2010). Skala ini terdiri dari 38 aitem dan 5 dimensi, serta memiliki format respon model Likert yang terdiri dari 0 (tidak pernah dilakukan), sampai 3 (selalu dilakukan). 5 dimensi yang terdapat dalam skala ini diantaranya adalah problem-focused koping (14 aitem, seperti bargained or compromised to get something positive from the situation), seek social support (6 aitem, seperti talked to someone to find out about the situation), blame self (3 aitem, seperti blamed yourself), wishful thinking (7 aitem, seperti, hoped a miracle would happen), dan avoidance (8 aitem, seperti went on as if nothing had happened). Semakin tinggi skor total dalam suatu dimensi menunjukkan tingginya tingkat jenis strategi koping dalam dimensi tersebut. 
Penelitian ini dilakukan pada 26 pelanggar Qanun Jinayat di Aceh. Dengan rentang usia dari
18-40 tahun.. Karakteristik subjek penelitian dapat dilihat dalam tabel 4.1.

Tabel 4.1 Karakteristik Subjek Penelitian

\begin{tabular}{ccccc}
\hline \multirow{2}{*}{ No. } & Karakteristik Usia & \multicolumn{2}{c}{ Jenis Kelamin } & \multirow{2}{*}{ Total } \\
\cline { 3 - 4 } & & Laki-laki & Perempuan & \\
\hline 1 & $18-20$ tahun & 2 & 2 & 4 \\
2 & $21-30$ tahun & 5 & 9 & 14 \\
3 & $31-40$ tahun & 6 & 2 & 8 \\
\hline
\end{tabular}

Adapun uji hipotesis dalam penelitian ini menggunakan metode Mann-Whitney Test dikarenakan data yang tidak terdistribusi normal atau jumlah subjek yang terbatas (Sujarweni, 2015).

\section{Hasil Penelitian dan Diskusi}

\begin{tabular}{|c|c|c|c|}
\hline No & $\begin{array}{l}\text { Dimensi } \\
\text { Strategi } \\
\text { Koping }\end{array}$ & Nilai Sig & Keterangan \\
\hline 1 & $\begin{array}{l}\text { Problem } \\
\text { Focused }\end{array}$ & $\begin{array}{l}\text { nilai asymp. sig. }(2- \\
\text { tailed) sebesar } 0,588 \\
(\mathrm{p}>0,05) \text {. }\end{array}$ & $\begin{array}{l}\text { tidak ada perbedaan yang signifikan } \\
\text { strategi koping dimensi problem } \\
\text { focused antara pelanggar Qanun } \\
\text { Jinayah laki-laki dan perempuan. }\end{array}$ \\
\hline 2 & $\begin{array}{ll}\text { Seek } & \text { Social } \\
\text { Support } & \end{array}$ & $\begin{array}{l}\text { nilai asymp. sig. }(2- \\
\text { tailed) sebesar } 0,551 \\
(p>0,05) .\end{array}$ & $\begin{array}{l}\text { tidak ada perbedaan yang signifikan } \\
\text { strategi koping dimensi seek social } \\
\text { support antara pelanggar Qanun } \\
\text { Jinayah laki-laki dan perempuan. }\end{array}$ \\
\hline 3 & Blame Self & $\begin{array}{l}\text { nilai asymp. sig. }(2- \\
\text { tailed) sebesar } 0,231 \\
(p>0,05) \text {. }\end{array}$ & $\begin{array}{l}\text { tidak ada perbedaan yang signifikan } \\
\text { strategi koping dimensi blame self } \\
\text { antara pelanggar Qanun Jinayah laki- } \\
\text { laki dan perempuan }\end{array}$ \\
\hline 4 & $\begin{array}{l}\text { Wishful } \\
\text { Thinking }\end{array}$ & $\begin{array}{l}\text { nilai asymp. sig. }(2- \\
\text { tailed) sebesar } 0,300 \\
(p>0,05) .\end{array}$ & $\begin{array}{l}\text { tidak ada perbedaan yang signifikan } \\
\text { pada strategi koping dimensi wishful } \\
\text { thinking antara pelanggar Qanun } \\
\text { Jinayah laki-laki dan perempuan. }\end{array}$ \\
\hline 5 & Avoidance & $\begin{array}{l}\text { nilai asymp. sig. }(2- \\
\text { tailed) sebesar } 0,036 \\
(\mathrm{p}<0,05) \text {. }\end{array}$ & $\begin{array}{l}\text { ada perbedaan yang signifikan pada } \\
\text { strategi koping dimensi avoidance } \\
\text { antara pelanggar Qanun Jinayah laki- } \\
\text { laki dan perempuan. }\end{array}$ \\
\hline
\end{tabular}

Jurnal Penelitian dan Pengukuran Psikologi, Vol. 8, 1, April 2019 
Koping adalah tindakan yang dipengaruhi oleh kepribadian individu yang melakukannya (McCrae \& Costa, 1986). Jika ditinjau dari perbandingan kepribadian berdasarkan Big Five Model (yaitu: Neuroticism, Extraversion, Openness, Agreeableness, dan Conscientiousness) antara laki-laki dan perempuan, penelitian yang dilakukan oleh South, Jarnecke, dan Vize (2018) menemukan bahwa tidak ada perbedaan Big Five Model pada laki-laki dan perempuan dewasa. Tidak adanya perbedaan ini dapat saja memengaruhi tidak adanya perbedaan strategi koping pada pelanggar Qanun Jinayah laki-laki maupun perempuan.

Dalam penelitian South, dkk (2018) menunjukkan bahwa tidak ada perbedaan strategi koping antara laki-laki dan perempuan dalam rentang usia dewasa. Sebagaimana dalam penelitian ini sebagian besar subjek berada dalam rentang usia dewasa. Penelitian Hampel dan Peterman (2005) menemukan bahwa baik remaja laki-laki dan perempuan, serta anak perempuan dari semua rentang usia memiliki nilai yang lebih rendah pada strategi koping adaptif dan lebih tinggi pada strategi koping yang tidak sesuai atau maladaptif. Contoh strategi koping yang adaptif adalah ketika individu menggunakan strategi koping yang berfokus pada masalah untuk dengan aktif menyelesaikan permasalahan yang dihadapinya, sedangkan contoh koping yang maladaptif adalah mengkonsumsi zat-zat terlarang untuk melarikan diri dari masalah yang dihadapi. Hasil ini menunjukkan bahwa tidak adanya perbedaan strategi koping antara laki-laki dan perempuan khususnya dalam rentang usia remaja yang juga termasuk ke dalam subjek penelitian.

Santacana, dkk (2012) dalam penelitiannya juga menemukan bahwa tidak adanya perbedaan jenis koping yang digunakan oleh laki-laki maupun perempuan. Hal ini juga mendukung hasil penelitian ini yang menunjukkan bahwa tidak adanya perbedaan strategi koping pada pelanggar Qanun Jinayah laki-laki dan perempuan pada strategi problem focused, seek social support, blame self, dan wishful thinking.

Salah satu hasil penelitian yang dilakukan oleh Peterson, Newton, Rosen, dan Skaggs (2006) menunjukkan bahwa perempuan lebih sering menggunakan strategi avoidance dibandingkan dengan laki-laki. Penelitian Gentry, dkk (2007) juga menemukan adanya perbedaan dalam penggunaan strategi avoidance antara laki-laki dan perempuan, dimana perempuan cenderung menggunakan strategi koping yang adaptif, sedangkan laki-laki cenderung menggunakan strategi yang maladaptif dan avoidance. Kedua penelitian tersebut mendukung hasil yang didapat dalam penelitian ini, yang mana terdapat perbedaan strategi koping avoidance pada pelanggar Qanun jinayah laki-laki dan perempuan.

Strategi koping yang tidak berbeda pada pelanggar Qanun Jinayah laki-laki maupun perempuan dapat dipengaruhi oleh faktor agama. Masyarakat Aceh mayoritas beragama Islam (Arifin \& Khambali, 2016). Arifin dan Khambali (2016) menyebutkan bahwa dalam konteks kehidupan, masyarakat Aceh dinilai taat dalam menjalankan ibadah atau kegiatan keagamaan, serta fanatik terhadap agamanya. Hal ini menggambarkan bahwa agama Islam sudah terbina dan telah bertapak kukuh dalam diri masyarakat Aceh (Arifin \& Khambali, 2016). Dalam Al-Qur'an Allah telah menjelaskan bahwa berbagai cara telah diatur bagi setiap individu untuk mengatasi masalah dalam hidup, Allah telah berjanji bahwa setiap masalah ada jalan keluarnya (Indirawati, 2006). Keyakinan bahwa setiap masalah ada jalan keluarnya membuat umat Islam selalu berusaha untuk mencari jalan keluar dalam setiap masalah yang dihadapi. Hal ini yang akhirnya mempengaruhi tidak adanya perbedaan strategi problem focused pada pelanggar Qanun Jinayah laki-laki maupun perempuan. Hal ini sejalan dengan pendapat yang dikemukakan oleh Lazarus dan Folkman (1984) bahwa kepercayaan kepada Tuhan merupakan salah satu faktor yang menentukan strategi koping individu.

Dalam Al-Qur'an surat Al-Maa'idah ayat 2 Allah berfirman yang artinya: 
“... Dan tolong menolonglah kamu dalam (mengerjakan) kebajikan dan taqwa, dan jangan tolong-menolong dalam berbuat dosa dan permusuhan..." (Al-Maa'idah: 2)

Dari ayat tersebut Islam mengajarkan kepada umatnya agar saling membantu orang lain. Ajaran ini dianut oleh pelanggar Qanun Jinayah sebagai umat muslim, yang akhirnya mendukung munculnya strategi seek social support baik bagi laki-laki maupun perempuan. Masyarakat Aceh yang dinilai taat dalam beragama (Arifin \& Khambali, 2016) menjalankan ajaran tersebut dan menjadi penyebab tidak adanya perbedaan strategi seek social support pada pelanggar Qanun Jinayah laki-laki maupun perempuan.

Faktor lain yang memengaruhi strategi koping adalah budaya (Lazarus \& Folkman, 1984). budaya Aceh mengajarkan dan menekankan beberapa karakter bagi masyarakat Aceh yaitu militan yang berarti memiliki semangat juang tinggi serta pantang menyerah, reaktif memiliki arti sebagai sikap awas terhadap harga diri yang keberadaannya dipertaruhkan dalam konstelasi sosial budaya yang taat dan Islami, konsisten dengan pendirian teguh dan tegas, serta yang terakhir adalah optimis (Yusoff, Awang, \& Ibrahim, 2014). Karakter masyarakat Aceh yang memiliki semangat juang tinggi dan optimis menjadikan masyarakat Aceh untuk tidak hanya berharap dan terus mencari dan menjalankan solusi yang dapat membantu dirinya menghadapi masalah. Hal inilah yang mempengaruhi tidak adanya perbedaan strategi koping problem focused dan wishful thinking pada pelanggar Qanun Jinayah laki-laki maupun perempuan.

Perbedaan dalam penggunaan strategi avoidance pada pelanggar Qanun jinayah laki-laki dan perempuan dapat dipengaruhi oleh depresi. Ardilla dan Herdina (2013) menyebutkan bahwa pelanggar hukum yang mendapatkan hukuman penjara akan mengalami permasalahan psikologis seperti depresi, kecemasan, fobia dan anti-social personality. Anbumalar, Dorathy, Jaswanti, Priya, dan Reniangelin (2017) menjelaskan bahwa strategi avoidance, seperti minum-minuman keras atau menolak keberadaan situasi yang menimbulkan stres, berkaitan dengan depresi. Buyuksahin (2009) dalam penelitiannya menjelaskan bahwa laki-laki cenderung lebih banyak mengonsumsi alkohol dan narkoba dibandingkan dengan perempuan.

Peneliti menyadari bahwa dalam melakukan penelitian ini terdapat banyak hambatan dan kekurangan. Diantara kekurangan dalam penelitian ini adalah sulitnya menemukan pelanggar Qanun Jinayat. Hal ini disebabkan oleh masa tahanan yang relatif singkat serta status pelanggar qanun yang hanya tahanan titipan. Periode masa tahanan yang relatif singkat menyulitkan peneliti untuk mendapatkan jumlah subjek sesuai dengan yang sudah ditentukan. Pelanggar yang sudah menjalani hukuman cambuk tidak lagi menjadi tanggung jawab baik Satpol PP dan WH, maupun Lapas tempat pelanggar ditahan untuk sementara waktu sehingga sulit untuk menemukan pelanggar Qanun Jinayah yang bersedia untuk berpartisipasi dalam penelitian ini.

\section{Kesimpulan}

Hasil penelitian ini menunjukkan bahwa tidak adanya perbedaan strategi koping problem focused, seek social support, blame self, dan wishful thinking pada pelanggar Qanun Jinayat baik laki-laki maupun perempuan, namun terdapat perbedaan dalam strategi koping avoidance pada pelanggar Qanun Jinayat laki-laki dan perempuan.

\section{Daftar Pustaka}

Aborisade, R. A., \& Fayemi, J. A. (2016) A qualitative exploration of the coping strategies of female offenders in nigerian prisons. International Journal of Criminology and Sociological Theory, 9, 1-14. 
Aldwin, C. M. (2007). Stress, Koping, and Development: An Integrative Perspective, Second Edition. New York: The Guildford Press.

Ardilla, F., \& Herdiana. I. (2013). Penerimaan diri pada narapidana wanita. Jurnal Psikologi Kepribadian dan Sosial, 2, 1-7.

Anbumalar, C., Dorathy, A. P., Jaswanti, V. P., Priya, D., \& Reniangelin, D. (2017). Gender differences in perceived stress levels and coping strategies among collage students. The International Journal of Indian Psychology, 4, 22-33.

Arifin, M., \& Khambali, K. B. M. (2016). Islam dan akulturasi budaya lokal di aceh (studi terhadap ritual rah ulei di kuburan dalam masyarakat pidie aceh). Jurnal Ilmiah Islam Futura, 15, 25-284

Arikunto, S. (2002). Metodologi Penelitian. Jakarta: PT. Rineka Cipta.

Azani. (2012). Gambaran psychological wellbeing mantan narapidana. Empathy, 1, 118.

Buyuksahin, A. (2009). Impact of self-monitoring and gender on coping strategies in inmates relationship among turkish university students. Sex Roles, 60, 708-720.

Dear, G. E., Slattery, J. L., \& Hillan, R. J. (2001). Evaluations of the quality of coping reported by prisoners who have selfharmed and those who have not. Suicide and Life-Threatening Behavior, 31, 442450 .

Dinas Syariat Islam Aceh. (2015). Hukum Jinayat \& Hukum Acara Jinayat. Banda Aceh: Penerbit Naskah Aceh.
Dwyer, A. L., \& Cummings, A. L. (2001). Stress, self-efficacy, social support, and coping strategies in university students. Canadian Journal of Counselling, 35, 208-220.

D'Zurilla, T. J., Olivares, A. M., \& Kant, G. L. (1998). Age and gender differences in social problem-solving ability. Personality and Individual Differences, 25, 241-252.

Gentry, L. A., Chung, J. J., Aung, N., Keller, S., Heinrich, K. M., \& Maddock, J. E. (2007). Gender differences in stress and coping among adults living in Hawai'i. Californian Journal of Health Promotion, 5, 89-102.

Gussak, D. (2009). Comparing the Effectiveness of Art Therapy on Depression and Locus of Control on Male and Female Inmates. The Arts in Psychotheraphy, 36, 202-207.

Hampel, P., \& Petermann, F. (2005). Age and gender effect on coping in children and adolescence. Journal of Youth and Adolescene, 34,73-83.

Indirawati, E. (2006). Hubungan antara kematangan beragama dengan kecenderungan strategi koping. Jurnal Psikologi Universitas Diponegoro, 3, 6992.

Kao, P., Chen, K. T., \& Craigie, P. (2017). Gender Differences in strategies for coping with foreign language learning anxiety. Social Behavior and Personality, 45, 205-210.

Kirchner, T., Forns, M., \& Mohino, S. (2008). Identifying the risk of deliberate self-harm among young prisoners by means of coping typologies. Suicide and LifeThreatening Behavior, 38, 442-448. 
Lazarus, R. S., \& Folkman, S. (1984). Stress, Appraisal, and Koping. New York: Springer.

Maheswari, K, K., \& Aruna, M. (2016). Gender difference and achievement motivation among adolescent school students. International Journal of Applied research, 2, 149-152.

McCrae, R. R., \& Costa, P. T. (1986). Personality coping and coping effectiveness in an adult sample. Journal of Personality, 54, 385-405.

Melendez, J. C., Mayordomo, T., Sancho, P., \& Thomas, J. M. (2012). Coping strategies: gender differences and development throughout the life span. The Spanish Journal of Psychology, 15, 1089-1098.

Mohino, S., Kirchner, T., \& Forns, M. (2004). Coping strategies in young male prisoners. Journal of Youth and Adolescene, 33, 4149.

Peterson, B. D., Newton, C. R., Rosen, K. H., \& Skaggs, G. E. (2006). Gender differences in how men and women who are reffered for IVF cope with infertility stress. Human Reproduction, 21, 2443-2449.

Reed, P., Alenazi, Y., \& Potterton, F. (2009). Effect of time in prison on prisoners' use of coping strategies. International Journal of Prisoner Health, 5, 16-24.

Santacana, M. F. I., Kirchner, T., Abad, J., \& Amador, J. A. (2012). Different between gender in coping: Different strategies or different stressor?. Anuario de psicologia, $42,5-18$.
Sawang, S., Oei, T. P. S., Goh, Y. W., Mansoer, W., Markhum, E., \& Ranawake, D. (2010). The ways of coping checklist revision-Asian version (WCCL-ASIAN): A new factor structure with confirmatory factor analysis. Applied Psychology: An International Review, 59, 202-219

South, S. C., Jernecke, A. M., \& Vize, C. E. (2018). Sex differences in the big five model personality traits: A behavior genetic exploration. Journal of Reasearch in Personality, 74, 158-165.

Sullins, D. P. (2006). Gender and religion: Deconstructing universality, constructing complexity. AJS, 112, 838-880.

Syofrianisda. (2017). Konsep sabar dalam alqur'an dan implementasinya dalam mewujudkan kesehatan mental. Hikmah: Jurnal Pendidikan Islam, 6, 137-155.

Ula, S. T. (2014). Makna hidup bagi narapidana. Jurnal Hisbah, 11, 15-36.

Utari, D. I., Fitria, N., \& Rafiyah, I. (2012). Gambaran Tingkat Kecemasan pada Warga Binaan Perempuan Menjelang Bebas di Lembaga Pemasyarakatan Perempuan Kelas II Bandung. Jurnal ilmu keperawatan, 1, 1-15.

Vitaliano, P. P., Russo, J., Carr, J. E., Maiuro, R. D., \& Becker, J. (1985). The ways of coping checklist: Revision and psychometric properties. Multivariate Behavioural Research, 20, 3-26. 
Vlassoff, C. (2007). Gender difference in determinants and consequences of health and illness. J Health Popul Nutr, 25, 4761. Retrieved from: https://www.ncbi.nlm.nih.gov/pmc/articles /PMC3013263/.

Welbourne, J. 1., Gangadharan, A., \& Esparza, C. A. (2016). Coping style and gender effect on attitudinal responses to incivility. Journal of Managerial Psychology, 31, 720-738.

Yusoff, N. B., Awang, M. I., \& Ibrahim (2014). Integrasi nilai islami dan budaya Aceh berdasarkan kurikulum karakter. Humas, $13,1-8$ 